Book reviewed:

Unemployment in Africa: a psychological perspective

Authors:

Webster Gonzo and Ilse Elisabeth Plattner

Publishers:

University of Namibia Press

Year:

2003

\section{Reviewed For:}

South African Journal of Industrial Psychology

\section{Reviewed By:}

Annemarie Joannides

Wits University

Title: Unemployment In an African country: a psychological perspective

By: Webster Gonzo and Ilse Elisabeth Plattner

Publishers: University of Namibia Press, 2003

Unemployment in an African country is a concisely written and well-structured book, which investigates the psychological impact of unemployment on Namibia's 'street unemployed'. This term refers to the large population of men who wait alongside the roads and at traffic intersections, in the hope of being offered causal employment. Essentially the books seeks to understand and evaluate the psychological experience of these men, in relation to several theoretical perspectives and with regards to the investigative research that was carried out by the authors.

The book uses several core concepts and theories, which underpin the authors' research aims and endeavours. The first of these is outlined in chapter two, and is the conceptual importance of being employed, and similarly the dire impact of being jobless, in a world of work. Chapter three investigates the psychological effects of unemployment from a theoretical perspective, and functions as a review of the relevant and informing literature on the topic of unemployment. Issues such as self-esteem, poverty, time management, social support and physical symptoms are explored, as well as the seminal study on the topic of unemployment, namely the Marienthal study. This piece of research essentially lays the foundation for the authors' investigative work. Chapter four attempts to provide explanations for the serious psychological impact of unemployment on the individual, and does so by addressing the benefits of being employed, as well as focusing on Seligman's Theory of Learned Helplessness. This theory was the theoretical framework that the authors used in order to ground and formulate their own research endeavours.

Chapter five is a thorough and very clear description of the research process that the authors undertook. Both qualitative interviewing and quantitative questionnaires were used to generate data, and the book outlines these steps in a very factual and directive manner. Included in this chapter is a brief overview of the difficulties that the researchers faced during the conducting of the study. This was very engaging from a reader's perspective because it provided an interesting insight into the practicalities and logistical limitations of conducting social research. The next chapter, which forms the bulk of the book, is made up of the various findings and results, which the research yielded. These results are very broad, and include the demographic profiling of the 'street unemployed', a description of their job-seeking behaviours and financial situations, a focus on the African social support system, as well as several other psychological concepts such as self-esteem, stress, coping, depression and psychosomatic symptoms. Other results also centre on alcohol consumption, experiences of time and future orientations of the 'street unemployed'. Lastly, chapter seven and eight are a summation, conclusion and then a set of practical recommendations, made by the authors to the governing bodies of Namibia.

The book is written fairly simply and allows the reader to easily grasp both the theoretical concepts and the research findings very easily. Essentially the text reads very much like a dissertation would, and perhaps more discussion and debate around the findings, as opposed to a mere representation of them, would have been more engaging for the reader. In terms of theoretical content, the literature is reviewed fairly superficially, thus this book would function as a good starting point for anyone interested in the topic, but would not provide any depth relating to any relevant psychological theory. An interesting and useful point to note is that the authors make use of graphs and graphic representations, in order to describe and explain their results. This made the grasping and comprehension of the study far easier for readers who are less familiar with social and academic research.

In terms of the actual research, the author's aims and methodologies are well defined and make conceptual sense. However the research is fairly simplistic, and does not offer the reader much beyond a statistical description of the psychological and social reality of Namibia's 'street unemployed'. It might have been useful for the authors to have looked for relationships or correlations between concepts, in order to create a more detailed, and intricate understanding and analysis of the unemployment phenomenon in Namibia.

In conclusion Unemployment in an African country is a suitable text for both academic students with a particular focus on the psychological effects of unemployment, and for the non-academic reader with just a casual interest in the topic. It is a well-written and fully comprehensive insight into Namibia's situation, but with relevance and applicability to other African countries. 


\section{REVIEW PANEL EDITION 31.1}

Mr COK Allen-Ile

Prof M De Beer

Prof GP De Bruin

Ms S Fischer

Ms Suki Goodman

Prof Crystal Hoole

Prof Rod Le Roux

Ms Karen Miller

Mr AP Moerdyk

Prof HJ Pietersen

Dr P Schaap

Prof John Slocum

Dr Chris van Tonder

Dr Marius Ungerer

Prof Koos Uys

Prof Johan Visser
Fort Hare University

UNISA

University of Johannesburg

Rhodes University

University of Cape Town

University of Pretoria

University of Kwazulu-Natal

Wits University

Rhodes University

University of the North

University of Pretoria

Southern Methodist University - Texas

University of Johannesburg

ABSA

University of Johannesburg

UNISA
Industrial Psychologist

Research Psychologist

Industrial Psychologist

Industrial Psychologist

Industrial Psychologist

Industrial Psychologist

Industrial Psychologist

Industrial Psychologist

Industrial Psychologist

Industrial Psychologist

Industrial Psychologist

Industrial Psychologist

Industrial Psychologist

Industrial Psychologist

Industrial Psychologist 